\title{
QUILOMBOS EDITORIAIS: PANORAMA E ESTRATÉGIAS
}

\author{
Luiz. Henrique Silva de Oliveira*
}

RESUMO: Este trabalho pretende resgatar as trajetórias e discutir as estratégias de atuação das casas ou quilombos editoriais responsáveis por veicular significativa parte da produção cultural afro-brasileira, especialmente a literatura. São exemplos: a Tipografia Fluminense de Brito e Cia. e a Empresa Tipográfica Dous de Dezembro; a Editora Pallas; a Mazza Edições; a Nandyala Editora; a Editora Ogum's Toques Negros; a Ciclo Contínuo Editorial e a Editora Malê. A análise da atuação das casas ou quilombos editoriais aponta para a natureza peculiar de sua postura diante: a) do mercado; b) da autonomia necessária à sua produção; c) do aporte de capital de operação; d) do papel de agente cultural necessário em um espaço bem demarcado etnicamente; e) do profissionalismo na condução das atividades, dada a ausência de políticas públicas de apoio às edições afro-brasileiras. O referencial teórico deste trabalho é formado por Pierre Bourdieu; Henrique Cunha Jr.; e Hernán López Winne e Victor Malumián,

PALAVRAS-CHAVE: Edição; Literatura afro-brasileira; Panorama; Quilombos editoriais.

O universo editorial, como campo, nos termos de Pierre Bourdieu, é definido por uma "rede ou configuração de relações objetivas entre posições definidas objetivamente nas determinações impostas aos seus ocupantes, agentes ou instituições, por sua situação" (BOURDIEU, 1982, p. 72). A situacionalidade, para o pensador, pauta-se pelo jogo de “legitimações, trocas e transferências de capitais de ordem simbólica” (BOURDIEU, 1982,

\footnotetext{
* Professor do Centro Federal de Educação Tecnológica de Minas Gerais (Ceft-MG), onde atua no Programa de Pós-Graduação em Estudos de Linguagens e na Graduação em Letras (Tecnologias de Edição). Doutor em Teoria da Literatura e Literatura Comparada pela Universidade Federal de Minas Gerais (UFMG).
} 
p. 72-73) capaz de ascender a uns à centralidade e a outros à periferia do próprio campo. Numa realidade cada vez mais codificada e endossada pelo discurso de natureza científica, podemos indagar se os conceitos compreendem bem a realidade de que falam. Forjados em grande medida por uma ciência que tem interesses e outras marcas, encobertos pela codificação, é de se indagar em que medida se faz necessária a problematização dos operadores teóricos, principalmente quando estes se referem a grupos e manifestações culturais considerados marginais.

No âmbito dos estudos sobre o nosso campo editorial, pensar as iniciativas de publicações de sujeitos afro-brasileiros, por meio dos operadores existentes, espelhados nos registros semânticos presentes em dicionários, parece redutor. Isso porque, por exemplo, ao pensarmos as casas e/ou iniciativas editoriais negras não basta levar em conta apenas o “estabelecimento que publica obras impressas, gravadas, etc.”, acepção corrente em todos os dicionários da língua portuguesa. Há que se levar em conta que, para além do estabelecimento, isto é, para além do empreendimento comercial, existe um conjunto de ações que escapam à geração de lucro econômico. Há todo um constructo de atividades de intervenção e, principalmente, de resistência ao que Pierre Bourdieu, em As regras da arte, chama de “arte burguesa”, ou seja, àquela direcionada ao grande mercado consumidor, a qual monopoliza, homogeneíza, autoriza e silencia discursos.

Parece apropriado referir-se às casas e/ou iniciativas editoriais negras como quilombos, entendendo este termo, em uma acepção ampliada. Henrique Cunha Jr. lembra que "o conceito de quilombo tem sido pensado no campo da identidade cultural, do território e da permanência histórica" ligado à "produção da identidade e da territorialidade" (CUNHA JR., 2012, p. 163). E é neste sentido, o da produção de identidade e da territorialidade, que me valho do quilombo como metáfora para compreensão das propostas de atuação das casas editoriais negras, ciente de que a episteme corrente no campo dos estudos sobre edição não consegue explicar a contento o objeto ao tratá-lo por meio da homogeneidade do conceito de editora, tal como os dicionários (ainda que específicos) o fazem. Pretendo, 
contribuir para a discussão propondo um rápido panorama das principais casas ou quilombos editoriais e suas estratégias de atuação quando o assunto é a publicação impressa de produtos culturais afro-brasileiros, em especial a literatura. Assim, espero fomentar o debate, ainda que ligeiramente, sobre as especificidades que fazem destas editoras singulares em suas propostas por meio do que chamo de quilombos editoriais.

Desta forma, por quilombos editoriais proponho entender um conjunto de iniciativas no campo editorial, comprometidas com a difusão de temas especificamente ligados ao universo afrodescendente, com claro propósito de alteração das configurações do imaginário social hegemônico. Possuem caráter deliberadamente independente. Seus autores são preferencialmente negros ou, em alguns casos, não negros comprometidos com o combate ao racismo em todas as suas formas. O catálogo é vasto e diverso, com ênfase em ciências humanas, cultura, artes e literatura. Possuem nítido projeto de intervenção político-intelectual a fim de criar debates e formar continuamente leitores sensíveis à diversidade em sentido amplo. Para além de casas de publicação, operam como territórios de ação e resistência ao bloqueio tácito no campo editorial brasileiro.

As casas ou quilombos editoriais fazem parte de um conjunto de redes de sociabilidade entre negros. Neste trabalho, as redes de sociabilidade são entendidas como iniciativas de arregimentação do coletivo afrodescendente para fins de convívio, atuação e resistência no âmbito da sociedade onde estão inseridas. São exemplos de redes de sociabilidade: a Imprensa Negra (séculos XIX e XX); a Frente Negra Brasileira (FNB); o Teatro Experimental do Negro (TEN); a série literária Cadernos Negros; o grupo Quilombhoje; o Movimento Negro Unificado (MNU). É importante salientar que as redes de sociabilidade negra podem até atuar no campo editorial, publicando autores, textos e obras diversos. Mas não se restringem à atividade editorial de publicação de obras de autores, tal como fazem os quilombos editoriais.

Os quilombos editoriais atuam exclusivamente no campo da publicação (principalmente individual de autores negros) e da intervenção cultural. Dentre eles, destacamos: a Tipografia Fluminense de Brito e Cia. e a Empresa Tipográfica Dous de Dezembro, criadas 
por Francisco de Paula Brito; a Editora Pallas; a Mazza Edições; a Nandyala Editora; a Editora Ogum's Toques Negros; a Editora Malê; e a Ciclo Contínuo Editorial. Todas estas casas ou quilombos editoriais, vastos e diversos entre si, apresentam um denominador comum: atuam de maneira independente em relação ao grande mercado da "arte burguesa" ou, se ainda quisermos, para além da "centralidade do campo literário", em termos bourdierianos.

Hernán López Winne e Victor Malumián (2016, p. 14) caracterizam as iniciativas editoriais em três categorias: a humanista; a capitalista selvagem; e a híbrida ou independente.

A iniciativa editorial capitalista selvagem está preocupada unicamente com o ganho financeiro. O produto editorial é ferramenta para a arrecadação e, geralmente, está pautado por assuntos ligados ao senso comum, à cultura de massa, aos produtos consagrados ou ao campo religioso, em determinados casos.

A iniciativa editorial humanista preocupa-se com os ganhos de ordem simbólica. Para ela, a obtenção de capital econômico não importa tanto, pois geralmente há fontes de onde se retira a subsistência (do editor e/ou da empresa). O lucro não é problema, tampouco é direção de suas ações. Interessa a esta iniciativa deixar sua marca por meio de bons produtos, os quais demonstrem rigoroso projeto gráfico e conteúdos relevantes à sociedade.

Por sua vez, há a iniciativa editorial híbrida ou independente. Este tipo de iniciativa procura conjugar as duas práticas anteriores, embora seja difícil manter este equilíbrio de atuação. Há preocupação com o catálogo, porque precisa ser atraente e possuir preço competitivo. De modo geral, a inciativa hibrida ou independente atua nas zonas intersticiais em relação às anteriores, isto é, nas franjas do amplo mercado e das grandes redes editoriais. As iniciativas independentes priorizam produtos pouco atraentes para o mercado de amplo capital, embora de interesse imediato por parte significativa de determinada zona desse campo. Como não está sujeita à obrigatoriedade de geração de volumes financeiros, concentra suas ações na construção de um catálogo de qualidade, mas sem descuidar do olhar 
sobre a rentabilidade dos projetos editoriais do presente, pois estes sustentam justamente os projetos do futuro. Aqui, o capital de giro é baixo. Nas palavras de López Winne e Malumián,

[o editor independente] persegue a auto-sustentabilidade e não depende de qualquer aporte de capital que provenha de fora de sua atividade editorial. Está comprometido com a difusão, por todos os meios possíveis, de seus autores, e a decisão sobre o que se publica ou rechaça está completamente submetida ao desejo de seu editor, sem nenhum tipo de condicionamento. É crucial a pretensão, a busca de encontrar na editora um modo de vida, um sustento econômico. (LOPEZ WINNE; MALUMIÁN, 2016, p. 14: tradução nossa)

Defendemos que os quilombos editoriais, enquanto redes de sociabilidade negras, conforme citado anteriormente, são exemplos desta vertente editorial independente. Mas quais seriam e o que caracterizaria uma iniciativa editorial independente e negra? $\mathrm{O}$ elenco destes quilombos editoriais e a breve caracterização de suas atividades e catálogos parece possibilitar responder, ainda que parcialmente, a estas perguntas.

Marcos iniciais destas casas ou quilombos editoriais foram a Tipografia Fluminense de Brito e Cia. e a Empresa Tipográfica Dois de Dezembro, dirigidas por Francisco de Paula Brito. A chegada da corte portuguesa ao Brasil, em 1808, ocasionou a instalação de diversos aparatos administrativos e de serviços, dentre eles a imprensa. Num primeiro momento, o Império, por meio da Imprensa Régia, monopolizava a produção oficial de impressos. Adiante, movidas a interesses políticos, pululam casas de imprensa no país. Resultante deste contexto, o jovem mulato Paula Brito (1809-1861), já nos anos de 1920, após aprender o ofício de tipógrafo na Imprensa Nacional, passa a trabalhar na empresa de René Ogier e, em seguida, no Jornal do Comércio, onde foi redator e tradutor.

Em 1832, Paula Brito começou sua primeira empresa gráfica, a Tipografia Fluminense de Brito e Cia., localizada no centro da cidade do Rio de Janeiro, então centro cultural do país. Esta casa editorial foi responsável pela publicação de $A$ Mulher do Simplício on $A$ Fluminense Exaltada, (1832-1846), primeiro jornal brasileiro dedicado ao público feminino. 
O compromisso com a defesa de seus irmãos de cor ganhou materialidade editorial a partir de 1833, quando veio ao público o jornal O Homem de Cor, o qual mais tarde passou a se chamar O Mulato ou $O$ Homem de Cor. A publicação propunha a o fim da escravidão, a inserção do negro no mercado de trabalho como assalariado, a industrialização do país e a ampliação do acesso a bens e serviços culturais à população. Arrisco dizer que o jornal instaurou, no campo editorial, a primeira rede de sociabilidade e resistência, em cujas páginas percebe-se uma ampla fratria entre negros brasileiros.

Como se pode perceber, as pautas de Paula Brito são incômodas à uma sociedade assentada em privilégios de raça e cor, para dizer o mínimo. Logo, os recursos financeiros para os projetos editoriais de Brito advieram sempre de suas próprias expensas ou da contribuição e seus autores, em alguns casos. Não é de se assustar, pois, com o caráter independente e com a dificuldade de sustentar suas publicações. O profissionalismo e a consciência de sua missão no campo cultural fizeram com que o talento de Paula Brito fundasse a primeira casa editorial propriamente brasileira (e uma das mais importantes de sua época): a Empresa Tipográfica Dous de Dezembro. Para fazer o empreendimento prosperar, o agenciamento cultural do nosso editor, poeta, contista, jornalista, tradutor e intelectual, levou-O a constituir redes envolvendo importantes intelectuais, artistas, figuras iminentes e até o próprio D. Pedro II, fato que o colocou em destaque no campo editorial e o possibilitou sua "militância quilombola" e editorial. O auge das atividades da Dous de Dezembro ocorreu entre os anos de 1830 a 1860 . Estima-se que tenham sido publicados uma centena de jornais e revistas e aproximadamente de 400 livros e folhetos ${ }^{1}$.

\footnotetext{
${ }^{1}$ Dentre os autores brasileiros publicados por Paula Brito, destacam-se: Joaquim Manoel de Macedo, Casimiro de Abreu, Gonçalves de Magalhães, José de Alencar, Martins Penna, Machado de Assis, Manuel de Araújo PortoAlegre, Domingos Alves Branco Moniz Barreto, Augusto Emílio Zaluar. Foi o editor de uma das primeiras peças de teatro brasileiro, Antônio José on o poeta e a Inquisição, de Gonçalves de Magalhães, em 1839; do que é considerado o primeiro romance brasileiro, $O$ filho do pescador, de Teixeira e Souza, em 1843; e daquela que é tida como a primeira ópera brasileira, a comédia lírica $A$ Noite de São João, de José de Alencar, apresentada sob a regência de Carlos Gomes, em 1860. Também é dele a primeira edição de Últimos cantos, de Gonçalves Dias, em 1851; a edição completa, em 2 volumes lançados em 1851, das Mauricianas, do Padre José Maurício Nunes Garcia; e a sexta edição de O Uraguai, de Basílio da Gama, lançada em 1855. Paula Brito foi ainda poeta, contista e tradutor. Entre seus contos publicados em jornais estão "O enjeitado" e "A mãe-irmã" (ambos no Jornal do Comércio - Rio de Janeiro, 1839). Já seus poemas foram compilados por Moreira de Azevedo, na obra póstuma Poesias de Francisco de 
Vale destacar que, em 1840, na livraria-editora de Paula Brito, foi criada, uma sociedade literária sem estatutos, na qual se reuniam romancistas, poetas, jornalistas, compositores, profissionais liberais, políticos e líderes da sociedade carioca: a Sociedade Petalógica. A principal proposta da Petalógica era a de promover uma série de encontros voltados ao "estudo da mentira" no campo político e social, o que, nas palavras de Bruno Martins, configura "a estratégia paradoxal de incorporar positivamente artifícios não escritos à ficção performática” (MARTINS, 2016, p. 141) daquela organização. Trata-se de uma ação intelectual de intervenção na realidade a fim de transformar o estado de coisas em favor dos fracos e oprimidos, principalmente aqueles de pele escura.

Se são os editores, conforme assinala Aníbal Bragança, que decidem que textos vão ser transformados em livros, pensando no "público a que devem servir", e se cabe a estes atores sociais o "lugar de decisão e de comando" (BRAGANÇA, 2005, p. 224), nota-se, pois, não apenas pioneirismo da Dous de Dezembro e de Paula Brito, mas a intervenção consciente deste editor-intelectual, cujas atitudes alteram as dinâmicas editoriais de seu tempo e contexto, mesmo contando com escassos recursos, o que reitera a necessidade de resistência diante das forças hegemônicas do campo editorial. O mesmo ocorrerá com outras casas ou quilombos editoriais. Ainda que elas só se tornassem possíveis mais de um século adiante.

Após as iniciativas de Paula Brito, o "vazio" de casas ou quilombos editorais prossegue até a década de 1970. Explica-se: a abolição da escravatura não significou a inserção do negro na sociedade de classes. Há ainda hoje carência de serviços essenciais a significativa parcela esta população, como acesso à educação de qualidade. Some-se a isso o papel repressivo a movimentos e associações negros. Vargas, por exemplo, fechou a Frente Negra Brasileira em 1938. Já os militares perseguiram exaustivamente lideranças do MNU e

Paula Brito, publicada em 1863. Brito traduziu diversos autores, como Frederic Soilié, Cordelier Delanoue, Pitre Chevalier, Alexandre Dumas, Emile Silvestre, Julis A. David e Cretineau July. 
outros movimentos sociais durante a ditadura (1964-1985). Ambas foram duros golpes em tentativas de intervenção cultural (e editorial) negras na realidade brasileira.

Por sua vez, a década de 1970 foi extremamente agitada quando o assunto é a arregimentação de grupos e coletivos negros, o que ajudou a tornar possível o surgimento de casas ou quilombos editoriais mais perenes. Nasciam movimentos como o MNU (Movimento Negro Unificado), formado no âmbito do CECAN (Centro de Cultura e Arte Negra), espaço onde os jovens negros, principalmente, reuniam-se a fim de promover discussões de ordem política, social e cultural. O movimento soul conquistava cada vez mais adeptos no âmbito da juventude negra, conforme lembra Carlindo Fausto Antônio (2005, p. 13). Além disso, o ano de 1978 demarcava os noventa anos de assinatura da Lei Áurea. Tudo isso sem desconsiderar os antecedentes editoriais listados anteriormente.

No contexto mundial, Aline Costa (apud RIBEIRO, 2008, p. 19) sublinha que a década de 1970 presenciou a independência de vários países africanos, como Angola e Moçambique. O ano de 1978 foi eleito pela ONU como "Ano Internacional Anti-apartheid”. No contexto estadunidense, eclodiam discussões pelos direitos civis e ações afirmativas, ao mesmo tempo em que movimentos como "Black Panthers" e o "Black Arts Movement" ganhavam adesão da juventude.

No Brasil, datam desta época as primeiras entradas de negros nas universidades, fato que permitiu maior contato deste coletivo populacional com diversas linguagens artísticas, tais como literatura, cinema, teatro, artes plásticas entre outras. Ressalte-se que as gerações anteriores aos anos de 1970 não puderam ter acesso a estes produtos e à formação universitária de maneira ampla. Todos estes acontecimentos levam à necessidade de produtos e produtores editoriais afeitos às discussões que circundam a população afro-brasileira. Daqui em diante, casas ou quilombos editoriais entram em cena graças à abertura proporcionada por esta decisiva época.

Resultante do acúmulo de discussões deste momento, surge a Pallas Editora, voltada ao universo cultural afrodescendente, fundada no Rio de Janeiro, no ano de 1975 por Antônio Carlos Fernandes. Hoje, a Pallas é dirigida por Cristina Fernandes Warth. Fazendo 
jus ao slogan de abertura de seu site "na vanguarda da cultura afro-brasileira" (http://www.pallaseditora.com.br/pagina/a_editora/2. Acesso: 08 mai. 2018), durante toda a trajetória da editora, nota-se a consciência da intervenção no campo cultural por meio do agenciamento de autores e textos num cenário informacional precário sobre a herança negra, como ocorre no Brasil. Daí que significativa parte do catálogo da casa editorial está voltada aos saberes africanos da diáspora e sua importância para a construção da nacionalidade brasileira. Conforme se lê no site da editora, "nossa casa editorial busca recuperar e registrar tradições religiosas, linguísticas e filosóficas dos vários povos africanos continuamente trazidos para o Brasil durante o regime escravista. Acompanhamos, ainda, as manifestações afro-brasileiras contemporâneas, valorizando-as como formas fundamentais de expressão da brasilidade" (http://www.pallaseditora.com.br/pagina/a_editora/2. Acesso: 08 mai. 2018).

O espectro do catálogo é vasto e diverso: religião, magia, tarô, yoga, saúde, cultura cigana, autoajuda, jogos, obras de referência, ciências sociais, antropologia, cinema, filosofia, não ficção, ficção e poesia. Dentre seus autores estão nomes de destaque, como Conceição Evaristo, Cidinha da Silva, Nei Lopes, Uelinton Farias, Paula Tavares (Angola), Ondjaki (Angola), Kangni Alem (Togo), dentre muitos outros.

Fundada em 1981, a Mazza Edições tem o compromisso explícito de publicar obras referentes à cultura afro-brasileira. Sua fundação ocorreu no período em que se rediscutia a redemocratização do país, já nos anos finais da ditadura militar. Neste sentido não é exagero dizer que a casa editorial opera como possibilidade rara de veiculação de discursos silenciados durantes os anos de chumbo, o que adianta uma de suas principais vocações no campo do livro: a mediação entre autores, obras e público.

Maria Mazarello Rodrigues é a fundadora da Mazza Edições. Mulher negra, militante e intelectual, sua trajetória é marcada pelo intenso envolvimento com questões de ordem social, política e cultural brasileiras. A formação de Mazza no campo editorial começa já na prática, tal como ocorre com grande parte dos editores (negros) brasileiros. 
Mazzarello iniciou sua imersão no universo editorial na Editora do Professor e, posteriormente, passou pela Editora Vega, nos anos 1960 e 1970. Em seguida, Maria Mazarello cursou o Mestrado em Editoração, em Paris. A formação especializada, ao meu ver, diferenciou e possibilitou a atuação profissional da editora no campo cultural e auxiliou na confecção de produtos editoriais de qualidade com recursos bastante restritos - o que não é novidade em se tratando de casas ou quilombos editoriais.

O catálogo da editora é pautado por três valores, com os quais seus autores comungam: ética, justiça e liberdade. Como quilombo editorial, sua atuação demonstra ciência de seu lugar "nas franjas" da arte burguesa ou do grande mercado, presidido, indiscutivelmente, pelo lucro. O capital financeiro é decisivo, mas sobretudo o capital simbólico pressuposto pelos valores da editora e espelhados nas obras de seus autores - em grande medida sustentam as linhas editoriais justamente pela autonomia decisória advinda da desvinculação de receitas do grande mercado. Se, por um lado, os recursos próprios ou dos autores limitam a ação da casa editorial, por outro garantem a independência de suas ações e posicionam a empresa num lugar singular e de resistência no campo cultural.

Acreditando nisso, conforme o próprio site da Mazza Edições, "propõe-se a atuar com sentido crítico para oferecer aos leitores e clientes obras que contribuam para uma melhor compreensão do passado, do presente e do futuro a ser construído" (http://www.mazzaedicoes.com.br/editora/. Acesso: 17 nov. 2017). E, mais adiante, assume-se não só como editora, mas também como "uma casa de cultura viva" (http://www.mazzaedicoes.com.br/editora/. Acesso: 17 nov. 2017).

O catálogo da Mazza Edições abrange antropologia, sociologia, história, educação, literatura brasileira (prosa e poesia contemporâneas), literatura infantil e infanto-juvenil. A editora conta ainda com um novo selo: o Peninha edições, voltado exclusivamente ao universo das crianças. Autores como Cuti, Edimilson de Almeida Pereira, Rosa Margarida de Carvalho Rocha, Leda Maria Martins e Cidinha da Silva, Patrícia Santana estão presentes nesta casa ou quilombo editorial. 
A Ciclo Contínuo Editorial, fundada em 2009 por Marciano Ventura, é a única que se assume de modo explícito como editora independente. Dedica-se à "publicação de obras literárias e pesquisas na área das Humanidades, com enfoque especial na produção cultural afro-brasileira" (https:/ / issuu.com/ciclocontinuoeditorial.nAcesso: 17 nov. 2017). Os aportes de capital provêm dos recursos providos pelas vendas de livros, das atividades realizadas pela editora ou dos próprios autores.

Dentre as atividades realizadas pela Ciclo Contínuo destacam-se seminários, encontro com autores e cursos livres sobre literatura. Bom exemplo é o "Com_textura Negra", evento por meio do qual, desde 2015, são discutidos temas referentes ao campo literário afro-brasileiro ${ }^{2}$.

O catálogo da casa ou quilombo editorial reúne autores como Lino Guedes, Oswaldo de Camargo, Cuti, Fábio Mandingo, Abelardo Rodrigues, Gerson Salvador, Márcio Folha, Ana Paula dos Santos Risos, Ângela Teodoro Grillo, Sérgio Ballouk, entre outros, divididos entre os gêneros literatura afro-brasileira (prosa e poesia) e ensaios.

A Nandyala Editora, fundada Belo Horizonte no início dos anos 2000 por Íris Amâncio e Rosa Margarida, publica autores africanos, caribenhos e brasileiros, num mix de assuntos que contemplam: biografias, testemunhos, memórias, estudos sobre África (histórias, filosofias e sociedades), relações étnico-raciais, diáspora negra, relações de gênero, artes, performances, religiosidades, literatura infantil, literatura juvenil, literatura afrobrasileira, literaturas africanas, crítica literária, educação, materiais pedagógicos, sustentabilidade e qualidade de vida. Nandyala significa "nascido em tempo de fome". Segundo o site da editora, sua missão é "colaborar com o efetivo respeito às diferenças, para uma vivência social sustentável na diversidade como exigência imperiosa do século XXI” (http:// nandyalalivros.com.br/missao. Acesso: 19 nov. 2017).

${ }^{2} \mathrm{O}$ site da Ciclo Contínuo traz o histórico de atividades culturais por ela promovidas: https://issuu.com/ciclocontinuoeditorial. 
Dentre seus principais autores destacam-se: Conceição Evaristo, Mirian Alves, Lia Vieira, Maria Elisa Santana, Benjamin Abras, Cidinha da Silva, Anderson Feliciano, Sandra Barroso, Madu Costa, só para citarmos alguns nomes. Entre os escritores africanos, salientamos Vera Duarte, Paulina Chiziane e Manuel Rui. A sessão de crítica cultural também é bastante robusta. Nela encontramos Aimé Césaire, Carlos Moore, Edimilson de Almeida Pereira, Erisvaldo Pereira dos Santos, Amauri Mendes, José Antonio Marçal, Rosa Margarida de Carvalho, Marcos Antônio Alexandre, Édimo de Almeida Pereira e Elzira Divina Perpetua, dentre outros.

A editora não recebe apoio de instituições de quaisquer ordens. As fontes financeiras advêm de seu próprio esforço comercial e de suas ações, como cursos de formação, palestras e consultorias. Para tal, entra em cena o Instituto Nandyala, fundado na Zona da Mata Mineira (Muriaé/MG), em 2011, e atualmente sediado em Belo Horizonte devido à ampliação do leque das suas atividades.

A Nandyala realiza ainda o projeto "Leitura em diferença", por meio do qual promove a circulação de seu catálogo, com destaque para o texto literário. No âmbito desta ação, encontram-se as "Ocupações Afroliterárias”, momentos específicos de oferta ao público de obras de autoras e autores negros de elevada qualidade conceitual e estético-discursiva, mas que quase não circulam pelo grande mercado editorial. Ainda neste sentido, a Nandyala realiza, desde 2012, a Fliafro (Festa Afroliterária do Brasil). Trata-se, pois, de uma casa ou quilombo editorial comprometido não só com a publicação, mas com a mediação cultural no seu mais amplo sentido.

A Editora Ogum's Toques Negros, fundada por Marcus Guellwaar Adún e Mel Adún, iniciou suas atividades no ano de 2014. O site da editora traz o tom empenhado de sua atuação e, ao mesmo tempo, sua concepção enquanto editora independente, entendendo-a como aquela que refuta o amparo do grande capital e procura realizar intervenções na cena cultural por meio de suas publicações e posicionamentos. Assim, lemos no portal: “a Editora Ogum’s nasce para contribuir com a interdição ao epistemicídio; impedir que 
sejamos apagadxs do mapa das letras" (http://www.editoraogums.com/somos-ogums. Acesso: 17 nov. 2017).

Guellwaar Adún ainda afirma o caráter independente de seu empreendimento editorial, movido pela luta contra o preconceito de cor, ao reiterar que "a Ogum's não é somente uma editora baiana, nordestina, negra e brasileira. Somos inegavelmente diaspóricos" ((http:/ / www.editoraogums.com/somos-ogums. Acesso: 17 nov. 2017). Ao reafirmar a diáspora, o editor assinala a vertente quilombola de sua atuação. A luta não é pequena. Garantir a produção e a circulação deste coletivo de escritores, tendo como aporte de capital os recursos dos editores e, ocasionalmente, dos autores, não é tarefa pouca. Ainda mais para uma casa ou quilombo editorial localizado fora do eixo Rio de Janeiro/São Paulo, onde o capital financeiro tende a se concentrar e logo, percebe-se a concentração editorial inclusive no universo das edições de afro-brasileiros, conforme apontaram XXX (2016) ${ }^{3}$.

Do ponto de vista do catálogo, a Ogum’s Toques Negros tem editado: literatura negra/afro-brasileira, ensaios, literatura infantil e literatura juvenil. Autores como Mirian Alves, Lívia Natália, Edimilson de Almeida Pereira, José Carlos Limeira, Dú Oliveira, Mel Adún e Guellwaar Adún marcam presença na casa editorial.

A Malê é uma editora e uma produtora cultural fundada por Vagner Amaro e Francisco Jorge, em agosto de 2015, no Rio de Janeiro. Foi planejada com objetivos bem específicos: "aumentar a visibilidade de escritores e escritoras negros contemporâneos; ampliar o acesso às suas obras e contribuir com a modificação das ideias pré-concebidas sobre os indivíduos negros no Brasil", conforme assinala Vagner Amaro em entrevista ao autor deste trabalho (http://www.letras.ufmg.br/literafro/editoras/1034-editora-male-entrevista-comvagner-amaro. Acesso 09 abr. 2018).

\footnotetext{
${ }^{3}$ Para se ter dimensão da concentração editorial XXX (2016) consideraram os contos e romances afro-brasileiros, publicados de 1859 a 2015. Das 88 publicações de contos, 28 aconteceram na cidade do Rio de Janeiro; 24 na cidade de São Paulo; e 13 na cidade de Belo Horizonte. Dos 61 romances publicados, 34 ocorreram na cidade do Rio de Janeiro; 14 em São Paulo.
} 
Nota-se a concepção de uma missão política bem delineada. A Malê não se preocupa somente com a edição e livros. A casa ou quilombo editorial aposta na formação de novos escritores, por meio de oficinas de escrita criativa. Organiza o Prêmio Malê de Literatura; realiza eventos literários; e promove a circulação de seus autores e oferece assessoria de imprensa aos autores/livros que edita.

O catálogo da Malê prioriza a edição de textos de literatura (romances, contos, poesia e ensaios) escritos por autoras a autores negros brasileiros. Dentre seus autores, salientamos Maria Firmina dos Reis, Conceição Evaristo, Tom Farias, Meimei Bastos, Cristiane Sobral, Lívia Natália, Sônia Rosa, Fábio Kabral, Muniz Sodré, Martinho da Vila, Rosane Borges e Cuti. Há ainda um selo infantil voltado para temas como cultura e histórias africana, cultura e história afro-brasileira e indígena, além de textos que tratam de identidade e alteridade: o Malê Mirim.

Segundo Vagner Amaro, a editora não recebe nenhum tipo de apoio, para nenhuma edição e nenhuma atividade. Todo o investimento tem sido feito pelos sócios. Os editores acreditam, por fim, na bibliodiversidade como forma de democratização do universo da leitura e mais amplo acesso ao campo dos bens simbólicos.

Após esta breve caracterização, é possível perceber que todas estas casas ou quilombos editoriais ultrapassam os limites de meros empreendimentos voltados ao comércio de impressos. Os quilombos editoriais promovem ações políticas e estéticas ao possibilitarem que discursos antes silenciados possam circular na sociedade brasileira. Ao se colocarem desta forma, assumem que o campo editorial, como todos os campos, são objetos de disputa e, no caso abordado neste trabalho, iniciativas de resistência. As estratégias empreendidas pelas casas ou quilombos editoriais dizem respeito a cinco aspectos. Em primeiro lugar, a atuação no mercado, que pressupõe a localização em um nicho específico, nas franjas no grande mercado, que não se interessa, ou não consegue atender a toda a vastidão de consumidores, ou não se interessa por determinados assuntos e debates. Em segundo lugar, requerem autonomia de atuação, isto é, independência do capital oriundo de grandes grupos empresariais, pois só assim têm liberdade para escolher o que publicar, uma vez que 
assumem praticamente sozinhos os riscos e méritos (quando muito dividem os riscos com os autores). Por isso, em terceiro lugar, o aporte de capital angariado quase que obrigatoriamente é todo reinvestido em publicações e ações de mediação cultural. Isso porque as casas ou quilombos editoriais, a fim de que consigam fazer seus textos circularem e, ao mesmo tempo, com o intuito de ampliarem seus mercados leitores/consumidores, precisam promover incansavelmente o fomento do debate público para garantir as agendas de ordem editorial. O resultado é o profissionalismo de seus editores, quarto aspecto, que aliam teoria e prática e confirmam compromisso com o coletivo afro-brasileiro no que podemos chamar de quinto aspecto: objetos editoriais de qualidade com o baixo recurso financeiro.

Portanto, as casas ou quilombos editoriais são iniciativas independentes, caracterizadas por deliberada resistência editorial, focadas em determinado nicho de mercado. Movimentam-se por meio de publicações e atividades político-intelectuais. Seus editores podem ser compreendidos como "incendiários culturais", ou seja, promotores do debate público com o intuito de alteração do estado de coisas. Todos eles trabalham pela bibliodiversidade e retroalimentação de seu nicho de mercado, porque as demandas estão longe de serem esgotadas num país ainda tão avesso ao enfrentamento do preconceito de cor. Os quilombos editoriais, dadas as caracterizações acima, fazem parte, pois, do conjunto de redes de sociabilidade negra no âmbito da história nacional.

\title{
“QUILOMBOS EDITORIAIS”: CHARACTERISTICS AND STRATEGIES
}

\begin{abstract}
This paper intends to propose to rescue the trajectories and to discuss the strategies for the performance of the editorial houses or "quilombos" responsible for the transmission of a significant part of Afro-Brazilian cultural production, especially literature. Examples are a Tipografia Fluminense de Brito e Cia. e a Empresa Tipográfica Dous de Dezembro; a Editora Pallas; a Mazza Edições; a Nandyala Editora; a Editora Ogum's Toques Negros; a Ciclo Contínuo Editorial e a Editora Malê. The analysis of the performance of the houses or editorial "quilombos" points to the peculiar nature of their attitude towards: a) the market; b) the autonomy necessary for its production; c) the contribution of working capital; d) the role of cultural agent necessary in an ethnically welldemarcated space; e) professionalism in the conduct of activities, given the absence of public policies to support Afro-Brazilian issues. The theoretical reference of this work is formed by Pierre Bourdieu; Henrique Cunha Jr.; and Hernán López Winne and Victor Malumián.
\end{abstract}


KEYWORDS: African-Brazilian literature; Edition; Panorama; “Quilombos editoriais”.

\section{REFERÊNCIAS}

ANTÔNIO, Carlindo Fausto. Cadernos Negros: esboço de análise. Campinas, SP: Unicamp, 2005. (Tese de doutorado).

BOURDIEU, Pierre. A economia das trocas simbólicas. Trad. Sérgio Miceli. 2 ed. São Paulo: Perspectiva, 1982.

BRAGANÇA, Aníbal. Sobre o editor: notas para sua história. Em Questão. Porto Alegre. v. 1, n. 2, p. 219-237, jul./dez. 2005.

COSTA, Aline. Uma história que está apenas começando. In RIBEIRO, Esmeralda; BARBOSA, Márcio. (ed.). Cadernos Negros: três décadas: ensaios, poemas, contos. São Paulo: Quilombhoje-SEPPIR, 2008.

CUNHA JUNIOR, Henrique Antunes. Quilombo: patrimônio histórico e cultural. Revista Espaço Acadêmico, n. 129, fevereiro de 2012, p. 158-167.

LÓPEZ WINNE, Hernán; MALUMIÁN, Víctor. Independientes, ¿de qué? Hablan los editores de América Latina. México: FCE, 2016.

MARTINS, Bruno Guimarães. Os artifícios da voz: Francisco de Paula Brito e a Sociedade Petalógica. Revista Tríade: Comunicação, Cultura e Mídia, v. 4, p. 135-149, 2016.

XXX; Panorama editorial da literatura afro-brasileira através dos gêneros romance e conto. Em tese. Belo Horizonte. v. 22 n. 3 set.-dez. 2016 p. 90-107.

\section{Sites consultados}

http://ciclocontinuoeditorial.com/blog-da-ciclo/

http:/ /www.editoraogums.com/somos-ogums

http:/ /www.letras.ufmg.br/literafro/editoras/1034-editora-male-entrevista-com-vagneramaro

http://www.mazzaedicoes.com.br/editora/

http://www.pallaseditora.com.br/pagina/a_editora/2

http://www.quilombhoje.com.br/quilombhoje/historicoquilombhoje.htm

https://issuu.com/ciclocontinuoeditorial

Recebido em: 02/08/2018.

Aprovado em: 26/11/2018. 